\title{
The Role of Mediterranean Fever Mutation in the Clinical Course and Pathogenesis of Ankylosing Spondylitis
}

\author{
Ali Erhan ÖZDEMİREL, ${ }^{1}$ Hatice Rana ERDEM, ${ }^{2}$ Barış NACIR, ${ }^{3}$ Aynur KARAGÖZ ${ }^{3}$ \\ ${ }^{1}$ Department of Physical Medicine and Rehabilitation, Division of Rheumatology, Medical Faculty of Ankara University, Ankara, Turkey \\ ${ }^{2}$ Department of Physical Medicine and Rehabilitation, Medical Faculty of Ahi Evran University, Kirşehir, Turkey \\ ${ }^{3}$ Department of Physical Medicine and Rehabilitation, Ankara Training and Research Hospital, Ankara, Turkey
}

\begin{abstract}
Objectives: This study aims to investigate the role of Mediterranean fever (MEFV) gene mutations in the pathogenesis and clinical progression of disease in ankylosing spondylitis patients.

Patients and methods: The study included 88 patients (60 males, 28 females; mean age $38.7 \pm 8.7$ years; range 19 to 56 years) diagnosed with ankylosing spondylitis according to modified New York criteria. The patients were evaluated for peripheral joint and hip joint involvement and treatment characteristics. Using multiplex/polymerase chain reaction reverse hybridization method, the presence of 12 different MEFV mutations was investigated.

Results: Of 29 patients, heterozygote mutation was detected in $24(83 \%)$, mutations in both alleles were detected in three (10\%), and combined heterozygote mutations were detected in two patients (7\%). Three most common mutations were M694V (11.3\%), E148Q (8\%), and V726A (4.5\%). In the group with mutations, symptoms had started earlier than in the other group, and the number of peripheral joints involved was higher. When both characteristics were compared with the characteristics of the group that did not have any gene mutations, the differences were statistically significant $(p<0.001$ and $p=0.044$, respectively). The highest correlation with the number of peripheral joints involved was determined for M694V mutation ( $p=0.034)$, while onset of symptoms at younger age was correlated with E148Q mutation $(p=0.010)$.

Conclusion: Based on the findings of this study and our clinical experience, it can be said that the clinical progression of ankylosing spondylitis patients with MEFV gene mutations is more severe, and this suggests that MEFV gene mutations may be contributive to ankylosing spondylitis pathogenesis.

Keywords: Ankylosing spondilitis; Familial Mediterranean fever; Mediterranean fever gene mutations.
\end{abstract}

Ankylosing spondylitis (AS) is the most frequently encountered disease in the spondyloarthritis group. Typically, it is a chronic disease which affects the spinal column and sacroiliac joints, entheses, and less commonly, the peripheral joints. The major symptoms of the disease are inflammatory back pain, spinal stiffness and loss of spinal mobility, which are caused by the presence of inflammatory activity that engenders structural damage, in the axial skeleton. ${ }^{1}$ In AS pathogenesis, genetic and environmental factors are thought to play an important role. ${ }^{2}$ Studies on AS genetics have shown a relationship between human leukocyte antigen B27 (HLA-B27), a component of major histocompatibility complex, with AS, and this relationship is the strongest association defined for AS yet. ${ }^{3}$ In fact, the concordance in monozygotic twin studies is reported as 70\%, indicating the $30 \%$ role of environmental factors involved in AS predisposition. Remarkably, the entire genetic predisposition cannot be explained solely by HLA-B27, because the concordance in dizygous twins positive for HLA-B27 is around $25 \% .^{4,5}$ Overall, among people positive for HLA$\mathrm{B} 27$, the risk of AS is $1.3 \% .^{6}$ This indicates the 
involvement of environmental and genetic factors other than HLA-B27 in AS development.

Previously, the Mediterranean fever (MEFV) gene on the short arm of the $16^{\text {th }}$ chromosome has been associated with familial Mediterranean fever (FMF) which is an auto-inflammatory periodical fever syndrome. ${ }^{7,8}$ There are data in the literature which support that pyrin protein encoded by MEFV gene takes a role in the intracellular control of inflammation. ${ }^{9}$ Point mutations defined for this gene disrupt the normal function of pyrin protein and probably lead to a more severe inflammatory response. Although MEFV gene mutations are most frequently seen in FMF patients, they are also seen in patients with other inflammatory diseases such as rheumatoid arthritis (RA), juvenile idiopathic arthritis, Behçet's disease and Henoch-Schönlein purpura. ${ }^{10-16} \mathrm{~A}$ recent study has shown that the presence of MEFV mutations associated with FMF in RA have been reported to be related to a more severe and erosive RA clinical profile. ${ }^{10}$ Similarly, among juvenile idiopathic arthritis patients with MEFV mutation, the clinical prognosis has been reported to be more severe compared with the ones without MEFV mutation. ${ }^{11}$

The association of FMF and spondyloarthropathy (SpA) has been a focus of discussion for years. According to the literature, FMF patients may present with a clinical profile similar to that of SpA including sacroiliac joint involvement and other clinical signs, while such cases are generally reported to be negative for HLA-B27. On the other hand, positivity for HLA-B27 is generally recognized as a coincidental association of AS and FMF. ${ }^{17-18}$ All these findings indicate that there might be common etiopathogenetic mechanisms involved in FMF and SpA diseases.

Mediterranean fever gene mutations may change the inflammatory response to infectious and inflammatory diseases and may contribute to the development of $\mathrm{AS} .{ }^{19}$ Moreover, they may influence disease course as well as disease activity, and so it is important to investigate the rate of MEFV mutations and the impact of these mutations on AS. ${ }^{10,16,19}$ Thus, in this study, we aimed to investigate the role of MEFV gene mutations in the pathogenesis and clinical progression of disease in AS patients.

\section{PATIENTS AND METHODS}

This single-center, cross sectional study included 88 patients $(60$ males, 28 females; mean age $38.7 \pm 8.7$ years; range 19 to 56 years) who were diagnosed with AS based on the 1984 modified New York criteria ${ }^{20}$ following MEFV gene analysis. The patients who met the revised Tel-Hashomer diagnostic criteria for $\mathrm{FMF}^{21}$ as well as those who had a history of FMF were excluded. The patients who gave consent to participate in the study were evaluated with regard to inclusion and exclusion criteria (Table 1). Approval for the study was obtained from the local ethics committee and written informed consents were obtained from all the participants.

The patients meeting the inclusion criteria underwent clinical evaluation and the data involving demographic characteristics, laboratory tests and physical examinations, clinical and functional activities, radiograms, and enthesis examinations were recorded. Clinical and functional activities were evaluated according to Bath Ankylosing Spondylitis Disease Activity Index (BASDAI), ${ }^{22}$ Bath Ankylosing Spondylitis Functional Index (BASFI) ${ }^{23}$ scores. Progression of the disease was evaluated by Bath Ankylosing Spondylitis Metrological Index score, ${ }^{24}$ whereas enthesitis was evaluated by Maastricht Ankylosing Spondylitis Enthesitis Score ${ }^{25}$ and radiological damage was assessed by modified Stoke Ankylosing Spondylitis Spine Score. ${ }^{26}$ Laboratory investigations including, erythrocyte sedimentation rate $(\mathrm{mm} / \mathrm{h})$, and C-reactive protein levels (mg/L), HLA-B27 and

\footnotetext{
Table 1. Inclusion and exclusion criteria

Inclusion criteria
Ankylosing spondylitis patients diagnosed according to the
modified New York criteria
History of initial therapy with non-steroidal anti-inflammatory
drug and/or sulfasalazine following the diagnosis of
ankylosing spondylitis
$\geq 18$ years of age
Consent for participation
Exclusion criteria
Presence of an inflammatory rheumatic disease other than
ankylosing spondylitis
Active infection
Presence of familial Mediterranean fever or its symptoms
Familial history of familial Mediterranean fever
$<18$ years of age
No consent
}


MEFV gene mutations were carried out on all participants.

Patients were evaluated with regard to involvement of the peripheral and hip joints, and treatment characteristics. Patients who had MEFV gene mutation and those who were non-carriers were compared according to the demographic, clinical, and laboratory parameters. The above mentioned parameters were also compared among the subgroups of carriers.

The files of all participants were reviewed and the most recent hemoglobin $(\mathrm{gr} / \mathrm{dL})$, leukocyte $\left(\mathrm{mm}^{3}\right)$, platelet $\left(\mathrm{mm}^{3}\right)$, erythrocyte sedimentation rate $(\mathrm{mm} / \mathrm{h}$, measured by Westergren method), and C-reactive protein $(\mathrm{mg} / \mathrm{dL})$ values were recorded. The analyses of MEFV mutations were performed by reverse hybridization method in the Molecular Tests Laboratory of Clinical Biochemistry Department at our hospital. Deoxyribonucleic acid was purified from the anticoagulated blood and amplification was carried out by the polymerase chain reaction method using primers of the second and $10^{\text {th }}$ exons of the MEFV gene. The amplification products were hybridized with test strips including oligonucleotide probes and mutation analysis was performed on 12 regions (M694V, E148 Q, V726A, F479L, R761H, M694I, K695R, P369S, M680I G/C, M680I G/A, A744S, 1692del).

\section{Statistical analysis}

The study data were analyzed by SPSS for Windows version 15.0 package program (SPSS Inc., Chicago, IL, USA). The Shapiro Wilk test was used to evaluate whether the distribution of continuous variables was close to normal or not. Descriptive statistics were expressed as mean \pm standard deviation or median (min.-max.) values, whereas categorical variables were presented as numerical and percentage (\%) values. The intergroup difference relative to mean values was analyzed by Student's t test and the intergroup difference relative to median values was evaluated by Mann-Whitney $U$ test. Categorical variables were analyzed by Pearson's chi-squared or Fisher's exact test. A value of $p<0.05$ was recognized as statistically significant.

\section{RESULTS}

The mean duration of disease was $9.1 \pm 5.1$ years. Positive HLA-B27 was determined in $71.6 \%$ of the patients and 29 AS patients (33\%) had MEFV gene mutation. Regarding the related MEFV gene mutations among those 29 patients, 10 (34.5\%) had heterozygous M694V, seven (24.1\%) had heterozygous E148Q, four (13.8\%) had heterozygous V726A, two (6.9\%) had heterozygous M6801G/C, and one (3.4\%) had heterozygous P3695 mutation. Only three (10.3\%) of the patients exhibited homozygous mutation: two (6.9\%) had homozygous M694V and one (3.4\%) had E148Q mutation. Two patients had a compound heterozygous mutation: one with a heterozygous M694V-E148Q and the other with a heterozygous M694V-M6801G/C mutation (Table 2). The incidences of subtypes of MEFV gene mutation are shown in Table 2. The distribution of the most frequent three MEFV mutations among the AS patients was as follows: M694V (11.3\%), E148Q (8\%) and V726A (4.5\%).

There were no significant differences between mutation carriers and non-carriers with

\begin{tabular}{|lccc}
\hline \multicolumn{3}{|c|}{ Table 2. Distribution of Mediterranean fever gene mutations in patients with ankylosing spondylitis } \\
\hline Mediterranean fever mutations & $\mathrm{n}$ & $\%(\mathrm{n}=29)^{*}$ & $\%(\mathrm{n}=88)^{* * *}$ \\
\hline Heterozygous M694V mutation & 10 & 34.5 & 11.3 \\
Heterozygous E148Q mutation & 7 & 24.1 & 8 \\
Heterozygous V726A mutation & 4 & 13.8 & 4.5 \\
Homozygous M694V mutation & 2 & 6.9 & 2.3 \\
Heterozygous M6801G/C mutation & 2 & 6.9 & 2.3 \\
Heterozygous M694V-E148Q mutation & 1 & 3.4 & 1.1 \\
Homozygous E148Q mutation & 1 & 3.4 & 1.1 \\
Heterozygous M694V-M6801G/C mutation & 1 & 3.4 & 1.1 \\
Heterozygous P3695 mutation & 1 & 3.4 & 1.1 \\
\hline * The distribution of Mediterranean fever mutation in 29 patients with Mediterranean fever mutation; ** The distribution of \\
Mediterranean fever mutation in all the patients $(\mathrm{n}=88)$.
\end{tabular}


Table 3. Demographic comparison of ankylosing spondylitis patient groups with and without Mediterranean fever mutations

\begin{tabular}{|c|c|c|c|c|c|c|c|c|c|c|c|}
\hline \multirow[t]{2}{*}{ Parameters } & \multicolumn{5}{|c|}{ Non-mutation $(\mathrm{n}=59)$} & \multicolumn{5}{|c|}{ Mutation $(\mathrm{n}=29)$} & \multirow[b]{2}{*}{$p$} \\
\hline & $\mathrm{n}$ & $\%$ & Mean \pm SD & Median & Min.-Max. & $\mathrm{n}$ & $\%$ & Mean \pm SD & Median & Min.-Max. & \\
\hline Age (years) & & & $39.3 \pm 8.2$ & & & & & $36.4 \pm 8.4$ & & & 0.28 \\
\hline Gender & & & & & & & & & & & 0.912 \\
\hline Male & 40 & 67.8 & & & & 20 & 69.0 & & & & \\
\hline Female & 19 & 32.2 & & & & 9 & 31.0 & & & & \\
\hline Diagnosis age & & & $32.2 \pm 7.0$ & & & & & $27.4 \pm 7.2$ & & & 0.004 \\
\hline Duration of disease & & & & 9.2 & $1-28$ & & & & 8 & 4-19 & 0.459 \\
\hline Age at onset of symptoms & & & $30.0 \pm 7.6$ & & & & & $24.4 \pm 7.1$ & & & $<0.001$ \\
\hline BASFI & & & & 2.9 & $0.8-5.5$ & & & & 3.0 & 1.8-5.5 & 0.220 \\
\hline BASDAI & & & & 3.3 & $1.2-5.8$ & & & & 3.5 & $2.8-7.2$ & 0.148 \\
\hline BASMI & & & & 2.7 & $0.0-8.0$ & & & & 3.5 & $0.0-7.0$ & 0.160 \\
\hline mSASSS & & & $16.2 \pm 9.6$ & & & & & $15.6 \pm 7.2$ & & & 0.773 \\
\hline MASES & & & $1.8 \pm 2.1$ & & & & & $2.3 \pm 2.2$ & & & 0.249 \\
\hline Chest expansion & & & & 3.3 & $1-6$ & & & & 3.2 & $0-5$ & 0.812 \\
\hline Lumbar schober & & & & 3.6 & $0.5-7$ & & & & 3.4 & $1-6$ & 0.286 \\
\hline Extra-articular involvement & 16 & 27.1 & & & & 8 & 27.6 & & & & 0.963 \\
\hline Erythrocyte sedimentation rate $(\mathrm{mm} / \mathrm{h})$ & & & & 21 & $2-88$ & & & & 23 & 3-78 & 0.739 \\
\hline C-reactive protein $(\mathrm{mg} / \mathrm{dL})$ & & & & 1.1 & $0.2-9.2$ & & & & 1.1 & $0.1-10.2$ & 0.922 \\
\hline
\end{tabular}

regard to age, gender, duration of disease, acute phase reactant levels, BASDAI, BASFI and Bath Ankylosing Spondylitis Metrological Index scores, Maastricht Ankylosing Spondylitis Enthesitis Score, and modified Stoke Ankylosing Spondylitis Spine Score. The mutation carriers group demonstrated earlier onset of symptoms and an earlier age of diagnosis. There was a statistically significant difference between the mutation carriers group and non-mutation carriers group in terms of those three characteristics. $(\mathrm{p}<0.001$ and $\mathrm{p}=0.004$, respectively) (Table 3).

Table 4 represents the relationship between hip involvement, treatment characteristics and involvement of peripheral joints of the mutation carrier and non-carrier patients. The mutation carriers group demonstrated involvement of a higher number of peripheral joints $(p=0.044)$ There was no statistically significant difference between the mutation carriers group and nonmutation carriers group with respect to hip involvement and treatment characteristics (Table 4).

The AS patients were divided into two groups based on being positive or negative for HLA-B27. In the HLA-B27 positive group, 23 (36.5\%) of 63 patients had MEFV mutation; and in the HLA-B27 negative group, six (\%24) of 25 patients. The two groups showed no statistically significant difference with regard to carrier rate of MEFV mutation ( $p>0.05)$. Similarly, the comparison of the two groups in terms of the three most common MEFV mutation subgroups in our study (M694V, E148Q, V726A, respectively), revealed

\begin{tabular}{|c|c|c|c|c|c|c|c|}
\hline \multirow[t]{2}{*}{ Parameters } & \multicolumn{3}{|c|}{ Non-mutation carriers $(n=59)$} & \multicolumn{3}{|c|}{ Mutation carriers $(\mathrm{n}=29)$} & \multirow[b]{2}{*}{$p$} \\
\hline & $\mathrm{n}$ & $\%$ & Mean \pm SD & $\mathrm{n}$ & $\%$ & Mean \pm SD & \\
\hline Peripheral joint involvement & 24 & 40.7 & \multirow{3}{*}{$2 \pm 3.2$} & 16 & 55.2 & \multirow{3}{*}{$4.7 \pm 5.7$} & 0.199 \\
\hline Number of peripheral joints & & & & & & & 0.044 \\
\hline Hip involvement & 15 & 25.4 & & 10 & 34.5 & & 0.376 \\
\hline NSAIDs and/or additional & & & & & & & \\
\hline TNF- $\alpha$ inhibitor to sulfasalazine & 10 & 16.9 & & 8 & 27.6 & & 0.245 \\
\hline
\end{tabular}




\begin{tabular}{|c|c|c|c|c|c|}
\hline \multirow[t]{2}{*}{ Variables } & \multicolumn{2}{|c|}{ HLA-B27 negative $(\mathrm{n}=25)$} & \multicolumn{2}{|c|}{ HLA-B27 positive $(n=63)$} & \multirow[b]{2}{*}{$p$} \\
\hline & $\mathrm{n}$ & $\%$ & $\mathrm{n}$ & $\%$ & \\
\hline Heterozygotic M694V mutation & 3 & 12 & 7 & 11.1 & 0.740 \\
\hline Heterozygotic E148Q mutation & 2 & 8 & 5 & 7.9 & 0.812 \\
\hline Heterozygotic V726A mutation & 1 & 4 & 3 & 4.8 & 0.617 \\
\hline
\end{tabular}

no statistically significant difference ( $p>0.05)$ (Table 5). Furthermore, there was no statistically significant difference between the overall study population $(\mathrm{n}=88)$ and the HLA-B27 negative group ( $n=25)$ relative to the incidence of these three mutations ( $p>0.05)$.

Ankylosing spondylitis patients with the three most common MEFV mutations (M694V, E148Q and V726A, respectively) were separately compared with the non-MEFV mutation group with regard to age of onset of symptoms, peripheral joint involvement, number of involved joints, hip joint involvement, and current treatments (Table 6). Furthermore, the patients with M694V and $\mathrm{E} 148 \mathrm{Q}$ mutations were compared with the patients with other MEFV mutations in terms of the same parameters (Table 6). The age of onset of symptoms was $39.3 \pm 8.2$ years in AS patients with no heterozygous MEFV mutation, whereas, it was $25.9 \pm 3.8$ years in AS patients with M694V mutation and $21.8 \pm 6.7$ in AS patients with heterozygous E148Q mutation. AS patients with M694V and E148Q mutations had a statistically significantly earlier age of onset of symptoms compared to the AS patients with no MEFV mutation $(p=0.022$ and $p=0.010$, respectively). The AS patients with heterozygous M694V mutation and heterozygous E148Q mutation were separately compared with the AS patients exhibiting other MEFV mutations with regard to age of onset of symptoms, and no statistically significant difference was determined

Table 6. Comparison of ankylosing spondylitis patients with M694V, E148Q and V726A mutation with ankylosing spondylitis patients without mutation together with comparison of ankylosing spondylitis patients with M694 and E148Q mutations with ankylosing spondylitis patients with other Mediterranean fever mutations with regard to age at onset of symptoms, peripheral joint involvement, number of involved peripheral joints, hip involvement, and use of tumor necrosis factor- $\alpha$ blockers

\begin{tabular}{|c|c|c|c|c|c|c|c|c|c|c|}
\hline \multirow[t]{2}{*}{ Groups } & \multirow[t]{2}{*}{$\mathrm{n}$} & \multirow{2}{*}{$\begin{array}{c}\begin{array}{c}\text { Age of onset } \\
\text { (year) }\end{array} \\
\text { Mean } \pm \text { SD }\end{array}$} & \multicolumn{2}{|c|}{$\begin{array}{c}\text { Peripheral joint } \\
\text { involvement }\end{array}$} & \multicolumn{2}{|c|}{$\begin{array}{l}\text { Number of peripheral } \\
\text { joints }\end{array}$} & \multicolumn{2}{|c|}{ Hip involvement } & \multicolumn{2}{|c|}{ TNF- $\alpha$} \\
\hline & & & $\mathrm{n}$ & $\%$ & Median & Min.-Max. & $\mathrm{n}$ & $\%$ & $\mathrm{n}$ & $\%$ \\
\hline Non-mutation & 59 & $39.3 \pm 8.2$ & 24 & 40.7 & 0 & $0-14$ & 15 & 25.4 & 10 & 16.9 \\
\hline $\begin{array}{l}\text { Heterozygotic M694V } \\
\text { mutation } \\
\text { Heterozygotic E148Q }\end{array}$ & 10 & $25.9 \pm 3.8$ & 7 & 70 & 4 & $0-20$ & 5 & 50 & 6 & 60 \\
\hline $\begin{array}{l}\text { mutation } \\
\text { Heterozygotic V726A }\end{array}$ & 7 & $21.8 \pm 6.7$ & 4 & 57.1 & 5 & $0-11$ & 2 & 28.6 & 6 & 85.7 \\
\hline mutation & 4 & $26.0 \pm 7.1$ & 3 & 75 & 5 & $0-12$ & 2 & 50 & 3 & 75 \\
\hline Other mutations* & 19 & $31.8 \pm 9.6$ & 9 & 47.4 & 0 & $0-16$ & 5 & 26.3 & 15 & 78.9 \\
\hline Other mutations ${ }^{* * *}$ & 22 & $34.3 \pm 7.9$ & 12 & 54.5 & 2 & $0-20$ & 8 & 36.4 & 15 & 68.2 \\
\hline$p^{* * *}$ & & 0.022 & \multicolumn{2}{|c|}{0.100} & \multicolumn{2}{|c|}{0.034} & \multicolumn{2}{|c|}{0.140} & \multicolumn{2}{|c|}{0.109} \\
\hline$p^{\dagger}$ & & 0.010 & \multicolumn{2}{|c|}{0.446} & \multicolumn{2}{|c|}{0.151} & \multicolumn{2}{|c|}{1.000} & \multicolumn{2}{|c|}{1.000} \\
\hline$p^{\ddagger}$ & & 0.152 & \multicolumn{2}{|c|}{0.305} & \multicolumn{2}{|c|}{0.135} & \multicolumn{2}{|c|}{0.293} & \multicolumn{2}{|c|}{0.546} \\
\hline$p^{\S}$ & & 0.085 & \multicolumn{2}{|c|}{0.433} & \multicolumn{2}{|c|}{0.377} & \multicolumn{2}{|c|}{0.244} & \multicolumn{2}{|c|}{0.390} \\
\hline$p^{\text {Tा }}$ & & 0.292 & \multicolumn{2}{|c|}{1.000} & \multicolumn{2}{|c|}{0.940} & \multicolumn{2}{|c|}{1.000} & \multicolumn{2}{|c|}{0.635} \\
\hline
\end{tabular}

TNF- $\alpha$ : Tumor necrosis factor-alpha; SD: Standard deviation; Min.: Minimum; Max.: Maximum; ${ }^{*}$ All the observed mutations other than heterozygotic M694V mutation; ** All the observed mutations other than heterozygotic E148Q mutation; *** Comparisons between non-mutation group and heterozygotic M694V group; † Comparisons between non-mutation group and heterozygotic E148Q mutation group; $\neq$ Comparisons between non-mutation group and heterozygotic V726A group; § Comparisons between heterozygotic M694V group and all other mutations; هा Comparisons between heterozygotic E148Q group and all other mutations. 
( $p=0.085$ and $p=0.292$, respectively) (Table 6). While the median value for the number of involved peripheral joints was $4(0-20)$ in AS patients with heterozygous M694V mutation, it was $0(0-14)$ in AS patients without MEFV mutations; the difference between these two groups was statistically significant $(p=0.034)$. No relationship similar to that detected between heterozygous M694V mutation and the number of involved peripheral joints in AS patients was found between patients with heterozygous E148Q and heterozygous V726A mutations, and AS patients without a MEFV mutation $(p=0.151$ and $p=0.135$, respectively) (Table 6). There was no statistically significant difference between AS patients with heterozygous M694V mutation and the group with other MEFV mutations in terms of the number of involved peripheral joints $(p=0.377)$.

\section{DISCUSSION}

Mediterranean fever mutations involved in the development of FMF lead to uncontrolled inflammatory response. ${ }^{27}$ In a study focusing on FMF patients and their first degree relatives during intervals between episodes, both groups were shown to have higher acute phase reactant levels compared with the healthy controls, probably due to subclinical proinflammatory cytokine release. ${ }^{28}$ This result suggests that MEFV may be counted among the genes that can affect the clinical course of inflammatory diseases other than FMF. Similarly, there are studies which indicate that MEFV mutations have a negative impact on inflammatory diseases such as Behçet's disease, ${ }^{13,15}$ RA, ${ }^{10}$ Henoch-Schönlein purpura, ${ }^{14}$ multiple sclerosis, ${ }^{29}$ and Crohn's disease. ${ }^{30}$

Ankylosing spondylitis and FMF are two clinical conditions affecting people of almost the same age group. The association of FMF with AS has been described in several previous reports ${ }^{17,31-33}$ although the pathogenic mechanism of this association still remains unknown. ${ }^{19}$

In a study by Yilmaz et al. ${ }^{34}$ conducted in 2001 , the MEFV carrier rate in the healthy population was $20 \%$. Studies performed in various regions of Turkey have produced similar values. ${ }^{35,36}$ In the current study, the MEFV mutation rate was 33\% among AS patients. Since these patients were from the same region as in the study by Yilmaz et al., ${ }^{34}$ the MEFV mutation rate among these people can be deemed to be raised. However, it is not possible to reach a definite conclusion because there was no control group in the current study. Similarly, Cinar et al. ${ }^{19}$ demonstrated the MEFV mutation rate in AS patients to be $30.5 \%$, but a control group was not used in that study either. Durmus et al. ${ }^{37}$ compared the MEFV mutation rate in AS patients with that of healthy individuals, but no statistically significant difference was determined.

There are few studies in the literature focusing on the association between AS and MEFV mutation as well as the impact of MEFV mutation over disease severity. ${ }^{19,37}$ In a study by Cinar et al. ${ }^{19}$ of 95 AS patients, MEFV mutation was shown to have no effect on disease severity with regard to clinical symptoms and laboratory values. Durmus et al. ${ }^{37}$ conducted a study on 80 AS patients and found that MEFV mutation was associated with higher BASDAI and BASFI scores. In the current study, MEFV mutation was found to have no influence over BASDAI, BASFI, and Bath Ankylosing Spondylitis Metrological Index scores, among AS patients. However, differing treatment protocols in our patients may be the underlying reason for this result, because although the difference was not statistically significant, a higher rate of tendency to use tumor necrosis factor- $\alpha$ inhibitor in patients with MEFV mutation was determined compared to those without MEFV mutation. These multiple and more aggressive treatment modalities may have resulted in stronger suppression of disease activity and functional status parameters in patients with mutations.

The most common MEFV mutations in our AS patients were M694V (11.3\%), E148Q (8\%), and V726A (4.5\%), respectively. While the M694V mutation carrier rate is 3\% in the healthy Turkish population, this rate increases to $50 \%$ in Turkish FMF patients. ${ }^{34}$ The carrier rate for E148Q mutation is $12 \%$ in the healthy Turkish population, but $3.5 \%$ in FMF patients. ${ }^{34}$ This remarkable increase of $\mathrm{M} 694 \mathrm{~V}$ mutation rate in AS patients compared to healthy individuals is associated with the fact that M694V mutation is seen in cases which show the highest penetration and most severe clinical course compared to other mutations. ${ }^{38-41}$ M694V mutation has been 
shown to be associated with early onset, episode frequency, arthritis, erysipelas-like erythema, and poor prognosis. ${ }^{34}$ On the other hand, E148Q mutation has not been shown to be associated with low penetration or severe clinical course in FMF patients. A previous controlled study investigating MEFV mutation rate in AS patients revealed increased M694V mutation rate in AS patients; the $\mathrm{M} 694 \mathrm{~V}$ rate was $2.9 \%$ in the control group and $12.4 \%$ in AS patients. ${ }^{42}$ In a study by Cinar et al., ${ }^{19}$ the M694V mutation rate in AS patients was $15.8 \%$, but there was no control group. In the current study, the M694V mutation rate among AS patients (11.3\%) was substantially higher compared to the overall carrier rate in the general healthy Turkish population (3\%). ${ }^{42}$ However, this result was not of statistical significance since a control group was not used in the current study, although it is evident that the M694V mutation rate shows an increase in AS patients similar to that in FMF patients, when compared to the general population. This finding suggests that M694V mutation is directly involved in the primary pathogenetic processes of AS. In the current study, the E148Q and V726A mutation rates were also investigated, but no significant increase was observed in AS patients compared to the increased rate exhibited by M694V mutation. The reason behind that may be that both of those mutations were of lower genetic penetrance compared to the M694V mutation.

This study indicated an association between MEFV gene mutations and clinical symptoms by showing a statistically significant direct correlation between the presence of MEFV mutation and the number of involved peripheral joints in AS patients $(p=0.044)$. The age at onset of symptoms was statistically significantly lower in AS patients with MEFV mutation than in patients without MEFV mutation $(p<0.001)$. Furthermore, any correlation between the three most common mutations (M694V, E148Q, and V726A, respectively), and the number of involved peripheral joints and age at onset of symptoms was investigated. The number of involved peripheral joints demonstrated a significant correlation only with M694V mutation $(p=0.034)$. The age at onset of symptoms showed a correlation both with M694V and E148Q mutations $(p=0.022$ and $p=0.010$, respectively). It is remarkable that a correlation was determined not only between age at onset of symptoms and
M694V mutation, but also between age at onset of symptoms and E148Q mutation ( $p=0.022$ and $p=0.010$, respectively); because E148Q mutation is known to be associated with low penetrance and a moderate level of clinical course in FMF patients. ${ }^{43}$ To date, there have been almost no studies showing that E148Q mutation is associated with a severe clinical course and early onset of symptoms in inflammatory diseases. In one such study, Rabinovich et al. ${ }^{10}$ investigated the impact of MEFV mutations on RA patients where E148Q mutation carriership was associated with a severe clinical course in RA patients. Since there are no similar reports in the literature supporting the association of E148Q mutation with early onset and poor clinical course, it is challenging to generalize the association between E148Q and early onset until further data has been gathered from more comprehensive studies focusing on this relationship.

Durmus et al. ${ }^{37}$ showed the relationship between MEFV mutation carriership and involvement of the hip joint in AS patients. Early onset, involvement of the hip joint, and oligoarticular involvement are known to be negative prognostic factors for AS. In the current study, MEFV mutation carriership was found to be associated with early onset and a higher degree of peripheral joint involvement in AS patients. Furthermore, although no statistical significance was determined, being a carrier of M694V mutation was observed to generate a particular tendency toward hip joint involvement in AS patients, while AS patients were also found to require more aggressive treatment. These results support the hypothesis that MEFV mutations, particularly M694 carriership, may be a risk factor for AS development. However, further controlled and prospective studies with larger patient groups are required to verify this.

For many years, there have been ongoing discussions on the association of FMF and SpA. In the literature, many cases of FMF and sacroiliitis are known to be negative for HLA-B27. Some argue that the development of SpA clinical profile in FMF patients can be differentiated from classic AS clinical profile via the absence of lumbar spinal involvement signs and HLA-B27 negativity. ${ }^{17,18,44}$ On the other hand, cases positive for HLAB27 are generally recognized as a coincidental association of AS and FMF. ${ }^{17}$ However, none of these assumptions are based on solid evidence, but 
only represent a tendency towards explanation. When these opinions are analyzed together with the results of this study, it can be said that FMF patients can be diagnosed with AS by modified New York criteria based on the symptoms of muscular/skeletal systems and radiological signs. Generally, cases exhibiting this association are observed to be negative for HLA-B27. This result suggests that etiological factors involved in FMF pathogenesis may also have a role in AS pathogenesis. On the other hand, there are opinions advocating that HLA-B27 positivity elevates the degree of sacroiliitis in FMF patients and leads to a more severe clinical course of FMF-related spondyloarthritis. ${ }^{17}$ These opinions underscore the likelihood of the presence of common etiopathogenetic processes in FMF and $\mathrm{SpA}$ disease groups, which are yet to be explained.

In a previous study, the M694V mutation was thought to be involved in the development of AS in patients negative for HLA-B27.42 In the current study, while the M694V mutation carrier rate was $11.3 \%$ in AS patients, it was $12 \%$ in HLA-B27 negative AS patients, with no statistically significant difference. However, considering the carrier rate $(3 \%)$ of M694V mutation in the healthy population, the increased M694V rate in HLA-B27 negative patients appears to be remarkable. Similar clusterings in AS patients negative for HLA-B27 and positive for E148Q or V726A mutations were observed.

The findings of this study suggest that the presence of MEFV mutation in AS patients is associated with a more severe clinical prognosis. Moreover, we believe that the presence of MEFV mutation will not only trigger the current inflammatory process associated with the AS, but may also act as a direct factor contributing to AS pathogenesis. M694V mutation appears to be the MEFV mutation type that is most closely associated with the pathogenetic mechanism in AS. In AS patients, early onset and aggressive clinical course are the most important indicators of disabilities which are likely to occur. Therefore, particularly in juvenile-onset AS patients, it is essential to determine prognostic factors and commence treatment urgently. MEFV mutation might be a factor which has a direct effect on AS pathogenesis, while showing a negative influence on the prognosis.
Therefore, in countries with high MEFV mutation rates such as Turkey, MEFV mutation screening should be included in routine tests. However, further national and multicenter studies including larger populations and prospective follow-up of patients are required to support these results.

\section{Declaration of conflicting interests}

The authors declared no conflicts of interest with respect to the authorship and/or publication of this article.

\section{Funding}

The authors received no financial support for the research and/or authorship of this article.

\section{REFERENCES}

1. Braun J, Sieper J. Ankylosing spondylitis. Lancet 2007;369:1379-90.

2. Arnett FC. Ankylosing spondylitis. In: Koopman WJ, editor. Arthritis and allied conditions. A textbook of rheumatology. Baltimore: Williams \& Wilkins 1997. p. $1197-208$.

3. Märker-Hermann E, Höhler T. Pathogenesis of human leukocyte antigen B27-positive arthritis. Information from clinical materials. Rheum Dis Clin North Am 1998;24:865-81.

4. Brown MA, Kennedy LG, MacGregor AJ, Darke C, Duncan E, Shatford JL, et al. Susceptibility to ankylosing spondylitis in twins: the role of genes, HLA, and the environment. Arthritis Rheum 1997;40:1823-8.

5. Breban M, Said-Nahal R, Hugot JP, Miceli-Richard C. Familial and genetic aspects of spondyloarthropathy. Rheum Dis Clin North Am 2003;29:575-94.

6. van der Linden SM, Valkenburg HA, de Jongh BM, Cats $\mathrm{A}$. The risk of developing ankylosing spondylitis in HLA-B27 positive individuals. A comparison of relatives of spondylitis patients with the general population. Arthritis Rheum 1984;27:241-9.

7. French FMF Consortium. A candidate gene for familial Mediterranean fever. Nat Genet 1997;17:25-31.

8. Balow JE Jr, Shelton DA, Orsborn A, Mangelsdorf M, Aksentijevich I, Blake T, et al. A high-resolution genetic map of the familial Mediterranean fever candidate region allows identification of haplotype-sharing among ethnic groups. Genomics 1997;44:280-91.

9. Bertin J, DiStefano PS. The PYRIN domain: a novel motif found in apoptosis and inflammation proteins. Cell Death Differ 2000;7:1273-4.

10. Rabinovich E, Livneh A, Langevitz P, Brezniak N, Shinar E, Pras M, et al. Severe disease in patients with rheumatoid arthritis carrying a mutation in 
the Mediterranean fever gene. Ann Rheum Dis 2005;64:1009-14.

11. Rozenbaum M, Rosner I. Severe outcome of juvenile idiopathic arthritis (JIA) associated with familial Mediterranean fever (FMF). Clin Exp Rheumatol 2004;22:75-8.

12. Ozen S, Karaaslan Y, Ozdemir O, Saatci U, Bakkaloglu A, Koroglu E, et al. Prevalence of juvenile chronic arthritis and familial Mediterranean fever in Turkey: a field study. J Rheumatol 1998;25:2445-9.

13. Atagunduz P, Ergun T, Direskeneli H. MEFV mutations are increased in Behçet's disease (BD) and are associated with vascular involvement. Clin Exp Rheumatol 2003;21:S35-7.

14. Gershoni-Baruch R, Broza Y, Brik R. Prevalence and significance of mutations in the familial Mediterranean fever gene in Henoch-Schönlein purpura. J Pediatr 2003;143:658-61.

15. Touitou I, Magne X, Molinari N, Navarro A, Quellec AL, Picco P, et al. MEFV mutations in Behçet's disease. Hum Mutat 2000;16:271-2.

16. Ozen S, Bakkaloglu A, Yilmaz E, Duzova A, Balci $\mathrm{B}$, Topaloglu $\mathrm{R}$, et al. Mutations in the gene for familial Mediterranean fever: do they predispose to inflammation? J Rheumatol 2003;30:2014-8.

17. Langevitz P, Livneh A, Zemer D, Shemer J, Pras M. Seronegative spondyloarthropathy in familial Mediterranean fever. Semin Arthritis Rheum 1997;27:67-72.

18. Balaban B, Yasar E, Ozgul A, Dincer K, Kalyon TA. Sacroiliitis in familial Mediterranean fever and seronegative spondyloarthropathy: importance of differential diagnosis. Rheumatol Int 2005;25:641-4.

19. Cinar M, Dinc A, Simsek I, Erdem H, Koc B, Pay $\mathrm{S}$, et al. The rate and significance of Mediterranean fever gene mutations in patients with ankylosing spondylitis: a three-month, longitudinal clinical study. Rheumatol Int 2008;29:37-42.

20. van der Linden S, Valkenburg HA, Cats A. Evaluation of diagnostic criteria for ankylosing spondylitis. A proposal for modification of the New York criteria. Arthritis Rheum 1984;27:361-8.

21. Livneh A, Langevitz P, Zemer D, Zaks N, Kees $\mathrm{S}$, Lidar $\mathrm{T}$, et al. Criteria for the diagnosis of familial Mediterranean fever. Arthritis Rheum 1997;40:1879-85.

22. Garrett S, Jenkinson T, Kennedy LG, Whitelock H, Gaisford P, Calin A. A new approach to defining disease status in ankylosing spondylitis: the Bath Ankylosing Spondylitis Disease Activity Index. J Rheumatol 1994;21:2286-91.

23. Yanik B, Gürsel YK, Kutlay S, Ay S, Elhan AH. Adaptation of the Bath Ankylosing Spondylitis Functional Index to the Turkish population, its reliability and validity: functional assessment in AS. Clin Rheumatol 2005;24:41-7.

24. Jenkinson TR, Mallorie PA, Whitelock HC, Kennedy LG, Garrett SL, Calin A. Defining spinal mobility in ankylosing spondylitis (AS). The Bath AS Metrology Index. J Rheumatol 1994;21:1694-8.

25. Heuft-Dorenbosch L, Spoorenberg A, van Tubergen A, Landewé $\mathrm{R}$, van ver Tempel $\mathrm{H}$, Mielants $\mathrm{H}$, et al. Assessment of enthesitis in ankylosing spondylitis. Ann Rheum Dis 2003;62:127-32.

26. Creemers MC, Franssen MJ, van't Hof MA, Gribnau FW, van de Putte LB, van Riel PL. Assessment of outcome in ankylosing spondylitis: an extended radiographic scoring system. Ann Rheum Dis 2005;64:127-9.

27. Touitou I. The spectrum of Familial Mediterranean Fever (FMF) mutations. Eur J Hum Genet 2001;9:473-83.

28. Tunca M, Kirkali G, Soytürk M, Akar S, Pepys $\mathrm{MB}$, Hawkins PN. Acute phase response and evolution of familial Mediterranean fever. Lancet 1999;353:1415.

29. Shinar Y, Livneh A, Villa Y, Pinhasov A, Zeitoun $\mathrm{I}$, Kogan A, et al. Common mutations in the familial Mediterranean fever gene associate with rapid progression to disability in non-Ashkenazi Jewish multiple sclerosis patients. Genes Immun 2003; 4:197-203.

30. Fidder H, Chowers Y, Ackerman Z, Pollak RD, Crusius $\mathrm{JB}$, Livneh A, et al. The familial Mediterranean fever (MEVF) gene as a modifier of Crohn's disease. Am J Gastroenterol 2005;100:338-43.

31. Duman I, Balaban B, Tugcu I, Dincer K. Familial mediterranean fever unusually coexisted in an ankylosing spondylitis patient. MEFV mutation has any role? Rheumatol Int 2007;27:689-90.

32. Keles I, Aydin G, Tosun A, Inal E, Keleș H, Orkun S. Familial Mediterranean fever and ankylosing spondylitis in a patient with juvenile idiopathic arthritis: A case report and review of the literature. Rheumatol Int 2006;26:846-51.

33. Uthman I, Hajj-Ali RA, Arayssi T, Masri AF, Nasr F. Arthritis in familial Mediterranean fever. Rheumatol Int 2001;20:145-8.

34. Yilmaz E, Ozen S, Balci B, Duzova A, Topaloglu $\mathrm{R}$, Besbas N, et al. Mutation frequency of Familial Mediterranean Fever and evidence for a high carrier rate in the Turkish population. Eur $\mathrm{J}$ Hum Genet 2001;9:553-5.

35. Lachmann HJ, Sengül B, Yavuzşen TU, Booth DR, Booth SE, Bybee A, et al. Clinical and subclinical inflammation in patients with familial Mediterranean fever and in heterozygous carriers of MEFV mutations. Rheumatology (Oxford) 2006;45:746-50.

36. Yigit S, Bagci H, Ozkaya O, Ozdamar K, Cengiz K, Akpolat T. MEFV mutations in patients with familial Mediterranean fever in the Black Sea region of Turkey: Samsun experience [corrected]. J Rheumatol 2008;35:106-13.

37. Durmus D, Alayli G, Cengiz K, Yigit S, Canturk F, Bagci H. Clinical significance of MEFV mutations in ankylosing spondylitis. Joint Bone Spine 2009;76:260-4. 
38. Dewalle M, Domingo C, Rozenbaum M, Ben-Chétrit E, Cattan D, Bernot A, et al. Phenotype-genotype correlation in Jewish patients suffering from familial Mediterranean fever (FMF). Eur J Hum Genet 1998;6:95-7.

39. Cazeneuve C, Sarkisian T, Pêcheux C, Dervichian M, Nédelec B, Reinert P, et al. MEFV-Gene analysis in armenian patients with Familial Mediterranean fever: diagnostic value and unfavorable renal prognosis of the M694V homozygous genotype-genetic and therapeutic implications. Am J Hum Genet 1999;65:88-97.

40. Shinar Y, Livneh A, Langevitz P, Zaks N, Aksentijevich I, Koziol DE, et al. Genotype-phenotype assessment of common genotypes among patients with familial Mediterranean fever. J Rheumatol 2000;27:1703-7.
41. Brik R, Shinawi M, Kepten I, Berant M, GershoniBaruch R. Familial Mediterranean fever: clinical and genetic characterization in a mixed pediatric population of Jewish and Arab patients. Pediatrics 1999;103:70.

42. Cosan F, Ustek D, Oku B, Duymaz-Tozkir J, Cakiris A, Abaci N, et al. Association of familial Mediterranean fever-related MEFV variations with ankylosing spondylitis. Arthritis Rheum 2010;62:3232-6.

43. Kastner DL, Hochberg MC, Silman AJ, Smolen JS, Weinblatt ME, Weisman MH, editors. In: Mosby Rheumatology. The hereditary periodic fevers, Edinburgh: 2003. p. 1716-34.

44. Lidar M, Kedem R, Mor A, Levartovsky D, Langevitz P, Livneh A. Arthritis as the sole episodic manifestation of familial Mediterranean fever. $J$ Rheumatol 2005;32:859-62. 